\title{
Teores de antocianinas, fenóis totais, taninos e ácido ascórbico em uva 'bordô' sobre diferentes porta-enxertos ${ }^{1}$
}

\author{
Maria Suzana Vial Pozzan², Gilberto Costa Braga ${ }^{3}$, Ariane Busch Salibe ${ }^{4}$
}

\section{RESUMO}

Este trabalho teve como objetivo avaliar o conteúdo de antocianinas, fenóis totais, taninos e ácido ascórbico, em variedade de uva 'Bordô', cultivada sobre os porta-enxertos '420A', 'IAC-766’ e 'Ripária-do-Traviú', em três períodos de colheita distintos. O experimento foi realizado em vinhedo de uva 'Bordô', no município de Missal, no Oeste do Paraná, na safra 2007/2008. O efeito dos porta-enxertos foi avaliado em três períodos de colheita, a partir da época de floração: 90 dias, com bagas em amadurecimento, tendendo ao roxo definitivo; 100 dias, com bagas totalmente roxas; e 110 dias, com bagas em sobrematuração. Foi utilizado o delineamento em blocos casualizados, em parcelas subdivididas no tempo. As variáveis analisadas foram sólidos solúveis, acidez titulável, índice de fenóis totais, antocianinas, taninos e teor de ácido ascórbico. Os resultados mostraram que, nos porta-enxertos '420A' e 'IAC-766', a uva 'Bordô' apresentou respostas similares em acúmulos de antocianinas, taninos, acidez titulável e sólidos solúveis, mas os acúmulos de fenóis totais, tanto na polpa, quanto na epiderme das bagas, foram maiores no ‘420A'. Ocorreram menores acúmulos de antocianinas, fenóis totais e taninos da epiderme da uva 'Bordô', quando enxertada em 'Ripária-doTraviú’. Acúmulos superiores de ácido ascórbico foram verificados nas uvas enxertadas em ‘IAC-766’. Há evidências que apontam o porta-enxerto ‘Ripária-do-Traviú’ como inferior aos demais, nos aspectos nutricional e enológico.

Palavras-chave: Vitis labrusca L., antioxidantes, maturação.

\section{ABSTRACT}

\section{Anthocyanins, total phenols, tannins and ascorbic acid in cv. Bordô grape on different rootstocks}

This study aimed to evaluate the content of anthocyanins, total phenols, tannins and ascorbic acid in grape grown onto '420A', 'IAC-766' and 'Ripária-of-Traviú' rootstocks in three different harvest periods. The experiment was conducted in 'Bordo’ grapes vineyard in Missal city, Paraná West, in the 2007/2008 harvest. The rootstock effect was evaluated in three periods after flowering: 90 days, with ripening berries , tending to a definite purple; 100 days, with berries completely purple, and 110 days, with berries overripening. The experiment was arranged in a split plot design in randomized blocks. The variables soluble solids, titratable acidity, total phenols index, anthocyanins, tannins and ascorbic acid were analyzed. The results showed that in the rootstocks '420A' and 'IAC-766', the 'Bordô' grape showed similar responses for anthocyanins, tannins, acidity and soluble solids accumulation, but the contents of phenolic compounds in the pulp and epidermis of berries were higher in '420A'. On the rootstock 'Ripária-do-Traviú', the 'Bordô' grape showed lower accumulation of anthocyanins, total phenols and tannins in the epidermis. Higher accumulations of ascorbic acid were found in 'Bordô' grapes on the rootstock 'IAC-766'. There is evidence suggesting that the 'Ripária-do-Traviú’ rootstock as inferior to others in nutritional and enological aspects.

Key words: Vitis labrusca L., antioxidants, maturation.

\footnotetext{
Recebido para publicação em 22/03/2012 e aprovado em 17/09/2012.

Retirado da dissertação da primeira autora.

2 Engenheira-Agrônoma, Doutoranda. Departamento de Ciências Agrárias, Universidade Estadual de Londrina (UEL), Rodovia Celso Garcia Cid/PR 445, Km 480, Caixa Postal 6001, 86051-980, Londrina, Paraná, Brasil. suzanavial@yahoo.com.br (autora para correspondência).

${ }^{3}$ Engenheiro-Agrônomo, Doutor. Centro de Ciências Agrárias, Universidade Estadual do Oeste do Paraná (Unioeste), Marechal Cândido Rondon, 1777, Centro, Caixa Postal 1008, 85960-000, Paraná, Brasil. gcb1506@gmail.com

${ }^{4}$ Engenheira-Agrônoma, Doutora. Departamento de Biotecnologia Vegetal, Universidade Federal de São Carlos, Campus de Araras, Rodovia Anhanguera, Km 174, s/n, 13600970, Araras, São Paulo, Brasil. absalibe@ig.com.br
} 


\section{INTRODUÇÃO}

No aspecto nutricional, as uvas estão entre as frutas que se destacam como fonte de compostos fenólicos, com importantes características biológicas, sendo destacadas suas propriedades antioxidantes (Wang et al., 1997; Teissedre \& Landrault, 2000). Os taninos, juntamente com as antocianinas, são as substâncias fenólicas do grupo dos flavonoides de maior concentração e de maior importância da uva e de vinhos (Abe et al., 2007).

Em uvas tintas, as antocianinas constituem componentes importantes para a produção de vinhos tintos, porque contribuem para os atributos sensoriais e, principalmente, para a coloração do vinho. A quantidade e a composição das antocianinas presentes nas uvas diferem de acordo com a espécie, variedade, maturação, condições climáticas e cultivar (Muñoz-Espada et al., 2004).

Os taninos podem ser divididos em dois grandes grupos: os taninos condensados (proantocianidinas) e os hidrolisáveis que, por hidrólise ácida, liberam ácidos fenólicos, como o gálico, caracterizando os galotaninos (Silva \& Silva, 1999). Os taninos condensados assumem importante papel nas características gustativas dos vinhos, uma vez que têm a capacidade de interagir com as proteínas salivares, sendo responsáveis por caracteres de amargor e adstringência no vinho e são, também, importantes na fixação da cor (Haslam \& Lilley, 1988).

A vitamina C (ácido ascórbico) é um dos principais indicadores do valor nutritivo em frutas, e seu efeito benéfico à saúde tem sido atribuído à sua atividade antioxidante (Rice-Evans et al., 1996). O teor de ácido ascórbico é amplamente influenciado por diversos fatores, dentre os quais variedade, fatores genéticos, estádio de maturação, nutrição da planta e o clima, sendo as uvas, em geral, fontes relativamente pobres em vitamina C (Chitarra \& Chitarra, 2005), que é, porém, um componente importante para a estabilidade dos compostos fenólicos das uvas, regulando a oxidação de polifenóis (Cheftel \& Cheftel, 1992).

Dentre as uvas americanas (V. labrusca) cultivadas no Brasil, o cultivar 'Bordô' tem-se destacado por sua elevada adaptação às condições climáticas brasileiras e por apresentar excelente fertilidade e apreciável tolerância a doenças fúngicas (Rizzon et al., 2000). Trata-se de cultivar utilizado basicamente para produção de vinhos e sucos (Pommer, 2003).

A escolha do porta-enxerto, via de regra, baseia-se na melhor adaptação às condições ambientais e à compatibilidade com a copa, sendo de fundamental importância na escolha e formação da muda (Gonçalves et al., 1999). O porta-enxerto pode interferir diretamente em algumas características químicas da baga, como o pH, a acidez titulável e o teor de sólidos solúveis. Outros aspectos, associados à qualidade da uva, que também devem ser levados em conta na escolha da melhor combinação copa/ porta-enxerto, são a absorção de nutrientes, o acúmulo de fenóis totais e o teor de antocianinas (Mota et al., 2009). Diversos trabalhos têm demonstrado diferenças na resposta da copa, quanto à qualidade da uva e do mosto, em função do porta-enxerto utilizado (Gonçalves et al., 1999; Alvarenga et al., 2002; Abe et al., 2007). Em razão disso, este trabalho teve como objetivo avaliar os conteúdos de antocianinas, índice de fenóis totais, taninos e ácido ascórbico da uva 'Bordô', amostrada em três períodos e cultivada sobre os porta-enxertos '420A', 'IAC-766' e 'Ripária-do-Traviú’.

\section{MATERIAL E MÉTODOS}

Amostras de uva 'Bordô' foram obtidas de vinhedo implantado, no ano 2000, no município de Missal, no Oeste do Paraná, situado a 25 05' 14'” de latitude Sul e 54 14 ' 43" de longitude Oeste e a $290 \mathrm{~m}$ de altitude. A região apresenta precipitação média anual de aproximadamente $2.000 \mathrm{~mm}$, clima subtropical úmido, com verões quentes e ocorrência pouco frequente de geadas, no inverno, com temperatura média anual ao redor de $22^{\circ} \mathrm{C}$. O mês mais quente é fevereiro, com média de $27^{\circ} \mathrm{C}$, e o mais frio é julho, com média de $15^{\circ} \mathrm{C}$. O solo predominante foi classificado como Latossolo Vermelho eutroférrico. As plantas estavam distribuídas, no campo, em espaçamento de 1,25 m x 2,00 m, conduzidas em espaldeira, no sistema de poda curta, com uma ou duas gemas e em sistema de cultivo agroecológico. As amostragens das uvas para as análises ocorreram na safra 2007/2008.

O experimento constou da avaliação do efeito dos porta-enxertos ‘420A', 'IAC-766’ e ‘Ripária-do-Traviú’ e da colheita em três períodos distintos, contados a partir da época de floração, sendo eles: 1) 90 dias (bagas em amadurecimento, tendendo ao roxo definitivo); 2) 100 dias (bagas totalmente roxa) e 3) 110 dias (bagas em sobrematuração).

Foi utilizado o delineamento em blocos casualizados, num total de sete blocos, com planejamento em parcelas subdivididas no tempo, com nove tratamentos, constituídos pela combinação dos três porta-enxertos, alocados nas parcelas, e dos três períodos de colheita, alocados nas subparcelas. Cada unidade experimental foi composta por cinco plantas, tendo sido observadas as três plantas centrais e, destas, amostrado um cacho por planta.

A amostra analítica foi constituída de 50 bagas, homogêneas em cor e tamanho, coletadas aleatoriamente de cada unidade experimental, após degrana manual nos cachos. Epiderme, polpa e sementes foram separadas manualmente.

O teor de sólidos solúveis ( ${ }^{\circ}$ Brix) da polpa das bagas foi determinado em refratômetro analógico de bancada Digit, modelo 2WAJ, e a acidez titulável foi determinada 
por titulação com $\mathrm{NaOH} 0,1 \mathrm{Mol} \mathrm{L}^{-1}$ e fenolftaleína como indicador (Carvalho et al., 1990).

Da epiderme e da polpa sem sementes, foram obtidos os extratos, conforme metodologia descrita por Silva et al. (2008) com modificações. Utilizou-se uma solução extratora hidroalcoólica de etanol $50 \%$ v/v, ajustada para pH 2 com tampão fosfato. As amostras adicionadas à solução extratora foram submetidas à agitação constante, sob aquecimento em banho-maria, por dez minutos. Após filtragem sob vácuo, os extratos obtidos foram armazenados a $5{ }^{\circ} \mathrm{C}$, para posterior análises de fenóis totais, antocianinas e taninos, que ocorreram em duplicata.

Na análise dos fenóis totais, foi utilizada a metodologia descrita por Silva et al. (2008). Utilizou-se $1 \mathrm{~mL}$ do extrato diluído em $100 \mathrm{~mL}$ de água destilada, para a leitura em espectrofotômetro. Calculou-se a absorbância a 280 ๆm, em cubeta de quartzo de $10 \mathrm{~mm}$ de percurso óptico, mediante a fórmula I280 = $\mathrm{A}_{280} \mathrm{x}$ F, em que ‘I280' representa $\mathrm{o}$ índice de fenóis totais, 'A' a absorbância e 'F' o fator de diluição da amostra.

O conteúdo total de antocianinas extraíveis foi determinado pelo método do $\mathrm{pH}$ diferencial, descrito por Orak (2007). As soluções extrato foram diluídas com tampão, para leituras de absorbância a 520 e 700 ๆm, em espectrofotômetro. Os valores de $\mathrm{pH}$ dos extratos diluídos foram de 1,0 (tampão cloreto de potássio $0,025 \mathrm{Mol} \mathrm{L}^{-1}$ ) e de 4,5 (tampão acetato de sódio $0,4 \mathrm{Mol} \mathrm{L}^{-1}$ ). Os valores de absorbância (A) das amostras diluídas foram calculados, como segue:

$$
\mathrm{A}=\left(\mathrm{A}_{\lambda, 520}-\mathrm{A}_{\lambda 700}\right)_{\mathrm{pH} 1.0}-\left(\mathrm{A}_{\lambda .520}-\mathrm{A}_{\lambda 700}\right)_{\mathrm{pH} 4.5}
$$

O conteúdo de antocianinas foi calculado como mg $100 \mathrm{~g}^{-1}$ de malvidina-3-glicosídeo, usando-se o coeficiente de absortividade molar $(\varepsilon)$ de 28000 e o peso molecular (PM) de 493,5 (Lee et al., 2008), conforme a seguinte fórmula:

$$
\text { Antocianinas }=\frac{A \times P M \times \text { fator de diluição } \times 1000}{\varepsilon \times 1}
$$

O conteúdo de taninos condensados foi determinado conforme metodologia descrita por Silva et al. (2009), em que o doseamento dos taninos proantociânicos totais baseia-se na reação de decomposição destes compostos em meio ácido e por ação do calor, medindo-se a absorbância das soluções resultantes. Foram preparadas duas amostras por tratamento, compostas por $4 \mathrm{~mL}$ do extrato, $2 \mathrm{~mL}$ de água destilada e $6 \mathrm{~mL}$ de $\mathrm{HCl}$ concentrado. Uma das amostras foi levada ao banho-maria, por 30 minutos, e a outra foi mantida à temperatura ambiente. Ao final, foi adicionado $1 \mathrm{~mL}$ de álcool etílico (95\%) às duas amostras, para solubilizar a cor vermelha formada. As absorbâncias das amostras foram lidas a 550 ๆm, em espectrofotômetro. O conteúdo de taninos, em $\mathrm{mg} \mathrm{g}^{-1}$, foi calculado a partir da diferença das absorbâncias (D) das duas amostras, pela fórmula:

$$
\text { Taninos }=19,33 \times D
$$

O teor de ácido ascórbico foi determinado pelo método titulométrico de Tillmans, modificado (Benassi \& Antunes, 1988), que se baseia na redução do 2,6diclorofenolindofenol-sódio pelo ácido ascórbico. Foram adicionados $5 \mathrm{~mL}$ do filtrado da amostra homogênea da polpa sem sementes, em erlenmeyer com $50 \mathrm{~mL}$ de ácido oxálico $1 \%$ e, depois, titulados com solução de 2,6diclorofenolindofenol $0,2 \%$, até coloração rosa persistente por 15 segundos e comparados com o padrão. Os resultados foram expressos em mg de ácido ascórbico por 100 $\mathrm{mL}$ da amostra e, as análises, feitas em duplicata.

Os efeitos dos porta-enxertos e dos períodos de colheita da uva 'Bordô' foram verificados por Análise de Variância para dados balanceados; para identificar diferenças significativas entre médias, conforme os desdobramentos das interações, foi adotado o teste de Tukey a $5 \%$ de significância e utilizado o pacote estatístico SAEG (2007).

\section{RESULTADOS E DISCUSSÃO}

O resultado da Análise de Variância mostrou interação não significativa, entre os fatores porta-enxerto e período de colheita, para acidez titulável da uva 'Bordô', indicando que a mudança do porta-enxerto não interfere na acidez das bagas, com o avanço no período de colheita. Resultados similares foram verificados por Abe et al. (2007), quando estudaram os porta-enxertos '420A' e '196-17', em uva 'Bordô', cultivada em Minas Gerais, e constataram efeito não significativo para a acidez titulável. Também não foi constatado efeito significativo do porta-enxerto sobre a acidez titulável das uvas, mas este fator influenciou significativamente no teor de sólidos solúveis apenas aos 90 dias da floração, com resultado superior para o porta-enxerto ' $420 \mathrm{~A}$ ', quando se compara com o dos demais porta-enxertos (Tabela 1).

Estudos sobre os efeitos do porta-enxerto em outras variedades copas foram verificados por Sato et al. (2008), em Rolândia, PR, com os porta-enxertos 'IAC-766' ' '420A', quando verificaram que não exerceram influência sobre as copas 'Isabel' e 'BRS-Rúbea', para as variáveis sólidos solúveis e acidez titulável. Orlando et al. (2008), estudando os cv. Cabernet Sauvignon e Syrah, sobre os porta-enxertos ‘Ripária-do-Traviú' e 'IAC-766’, em Jundiaí, SP, não observaram efeito dos porta-enxertos no teor de sólidos solúveis e na acidez titulável das bagas.

Considerando-se o aspecto climático, a maturação da uva é marcada pelo período mais ensolarado do ano, quan- 
do ocorre elevação da temperatura, determinando maior acúmulo de açúcares e diminuição da acidez, por degradação de ácidos orgânicos (Santana et al., 2008). Além disso, elevados volumes de precipitação durante o período de maturação são prejudiciais, pois resultam em menores teores de açúcares solúveis na baga (Mandelli et al., 2008). Neste sentido, os porta-enxertos testados apresentaram as mesmas características de adaptação frente às variações climáticas típicas de verão, ocorridas na época de maturação e colheita da uva 'Bordô', pois, conforme destacado na Tabela 1, não influenciaram as variáveis sólidos solúveis e acidez titulável das bagas, especialmente no período de amadurecimento pleno, aos 100 dias da floração.

Os efeitos significativos verificados para o período de colheita (Tabela 1), revelando aumento no teor de sólidos solúveis e diminuição da acidez titulável, com o avanço da maturação, refletem respostas fisiológicas normais e ideais, na fase de amadurecimento da uva (Pommer, 2003). Os níveis de sólidos solúveis e acidez titulável, alcançados aos 100 e 110 dias de colheita (Tabela 1), são considerados desejáveis para fins de vinificação (Rizzon \& Miele, 2004), pois o acúmulo de açúcares, além de ser considerado o fenômeno fisiológico mais importante da maturação de uvas, pela quantidade de álcool que dele deriva no processo de vinificação, também serve de substrato metabólico para a síntese de compostos como polifenóis, antocianinas e outros relacionados com o aroma da uva (Abe et al., 2007).

Para as uvas cultivadas sobre os porta-enxertos ' $420 \mathrm{~A}$ ' e 'IAC-766', os acúmulos de antocianinas nas bagas foram estatisticamente iguais (Tabela 2), mas foram bem superiores aos das cultivadas sobre o porta-enxerto 'Ripária-do-Traviú', nos três períodos de colheita avaliados. Mota et al. (2009), avaliando a influência de diferentes porta-enxertos sobre as características da uva 'Bordô' cultivada em Caldas, MG, e sob adubação convencional, verificaram que as da uva cultivada sobre o porta-enxerto 'IAC-766' não diferiu das cultivadas sobre 'Ripária-doTraviú' em acúmulo de antocianinas de uvas 'Bordô'. Esse acúmulo foi superior ao das uvas cultivadas sobre o porta-enxerto '420A', contrastando com os resultados encontrados neste estudo, para as cultivadas sobre 'Ripária-
do-Traviú', que foram de menor acúmulo de antocianinas nas bagas. Isso reflete possível interferência das condições climáticas na resposta de adaptabilidade do portaenxerto 'Ripária-do-Traviú', pois, em Caldas, MG, segundo os mesmos autores, o clima é mais frio (média anual de $\left.18^{\circ} \mathrm{C}\right)$, o volume de precipitações é menor (1600 mm) e a altitude é maior (1150 m), em comparação com a região de Missal, PR, onde este experimento foi realizado.

Mota et al. (2009) verificaram, também, que as uvas cultivadas sobre os porta-enxertos 'IAC-766' e 'Ripáriado-Traviú' destacaram-se no acúmulo de antocianinas das bagas e foram aquelas cujo vigor vegetativo foi menor, e associaram este fato à maior síntese de compostos fenólicos na epiderme, pois, provavelmente, tiveram menor sombreamento nos cachos, induzindo menor competição por luz entre órgãos vegetativos e produtivos da planta, sendo mais eficientes na síntese de antocianinas.

Abe et al. (2007), em experimento similar, observaram diferenças significativas no teor de antocianinas na baga da uva 'Bordô', com acúmulos superiores para as uvas cultivadas sobre o porta-enxerto '420A', dando indícios relevantes de sua superioridade frente a outros porta-enxertos. Resultado semelhante pode ser verificado na Tabela 2, com acúmulos significativamente superiores de antocianinas da epiderme da uva 'Bordô', quando enxertada sobre o porta-enxerto ' $420 \mathrm{~A}$ ', comparados com os das cultivadas sobre 'Ripária-do-Traviú'.

Os aumentos significativos de antocianinas, para as uvas cultivadas sobre os porta-enxertos ' $420 \mathrm{~A}$ ' e 'IAC766', do primeiro para o segundo período de colheita avaliados (Tabela 2), são indícios de mudanças de cor dos frutos, quando assumem a cor roxa. Considerando-se o aspecto bioquímico do metabolismo da uva, esses resultados estão de acordo com o esperado para o cultivar 'Bordô', pois, com o amadurecimento das uvas tintas, ocorre aumento no teor de pigmentos antociânicos, com consequente aumento na coloração da epiderme das bagas (Pommer, 2003). No entanto, as uvas cultivadas sobre o porta-enxerto 'Ripária-do-Traviú' não apresentaram a mesma resposta fisiológica em síntese de antocianinas, pois não foram constatadas variações significativas ( $\mathrm{p}$ > 0,05 ) entre os períodos avaliados. Explicação para esses resultados pode estar relacionada com a característica de

Tabela 1. Acidez titulável e sólidos solúveis da polpa da uva 'Bordô’ em diferentes porta-enxertos e períodos de colheita

\begin{tabular}{|c|c|c|c|c|c|c|}
\hline \multirow{2}{*}{$\begin{array}{l}\text { Períodos de } \\
\text { colheita (dias) }\end{array}$} & \multicolumn{3}{|c|}{ Acidez titulável (mEq $\left.\mathbf{L}^{-1}\right)$} & \multicolumn{3}{|c|}{ Sólidos solúveis ( $\left.{ }^{\circ} \mathrm{Brix}\right)$} \\
\hline & '420A' & 'IAC-766' & 'Ripária-do-Traviú' & '420A' & 'IAC-766' & 'Ripária-do-Traviú' \\
\hline 90 & $82,68^{\text {aA }}$ & 85,08 aA & 81,43 aA & 14,26 bA & 12,22 ьв & 12,90 ьв \\
\hline 100 & 52,85 bA & $59,92 \mathrm{bA}$ & 58,15 bA & $15,43 \mathrm{abA}$ & 14,96 aA & 14,80 aA \\
\hline 110 & 50,77 bA & 50,99 bA & $41,56^{\mathrm{cA}}$ & 16,06 aA & 15,21 aA & 15,76 aA \\
\hline $\mathrm{CV} \%$ & & 15,12 & & & 5,46 & \\
\hline
\end{tabular}

Médias seguidas da mesma letra minúscula, na coluna, e da mesma letra maiúscula, na linha, não diferem a p < 0,05, pelo teste Tukey.

Rev. Ceres, Viçosa, v. 59, n.5, p. 701-708, set/out, 2012 
adaptação desse porta-enxerto às condições ambientais, quando se compara com os resultados das uvas cultivadas sobre os outros porta-enxertos, comprometendo tanto a síntese total de antocianinas, quanto a sua evolução durante o período de maturação.

Resultado relevante foi verificado para o efeito do porta-enxerto sobre o teor de ácido ascórbico nas bagas (Tabela 2), bem como para a ocorrência de interação significativa $(\mathrm{p}<0,05)$ entre os fatores avaliados. Constataram-se acúmulos de ácido ascórbico significativamente superiores para o 'IAC-766', frente aos dos demais portaenxertos, com exceção do 'Ripária-do-Traviú', aos 90 dias da floração.

Não houve efeito significativo do período de colheita para as uvas cultivadas sobre o porta-enxerto 'IAC-766', cujos valores médios de ácido ascórbico observados foram 8,23, 9,57 e 7,89 mg $100 \mathrm{~mL}^{-1}$ aos 90, 100 e 110 dias da colheita, respectivamente. Comportamento similar ocorreu para as cultivadas sobre '420A', com 3,33, 4,94 e 5,0 mg $100 \mathrm{~mL}^{-1}$, respectivamente, nos mesmos períodos. Esses resultados indicam que as características de adaptação do 'IAC-766’ e do ‘420A' influenciaram em demandas oxidativas insuficientes para diminuir o conteúdo de ácido ascórbico, pois, segundo Pommer (2003), o teor de ácido ascórbico começa a diminuir graças ao aumento na demanda de processos oxidativos relacionados com o metabolismo das bagas, especialmente depois que atingem o amadurecimento, ou seja, quando ocorre aumento no teor de antocianinas (nas variedades tintas) e de açúcares (glicose e frutose), assim como diminuição pronunciada da acidez. Apenas para as uvas avaliadas sobre 'Ripária-do-Traviú' ocorreram diminuições nos teores de ácido ascórbico, evidenciando o comportamento diferenciado deste porta-enxerto.

Tabela 2. Antocianinas da epiderme e ácido ascórbico da uva 'Bordô' em diferentes porta-enxertos e períodos de colheita

\begin{tabular}{|c|c|c|c|}
\hline \multirow{2}{*}{$\begin{array}{l}\text { Períodos de } \\
\text { colheita } \\
\text { (dias) }\end{array}$} & \multicolumn{3}{|c|}{ Antocianinas da epiderme (mg $100 \mathrm{~g}^{-1}$ ) } \\
\hline & '420A' & 'IAC-766' & 'Ripária-do-Traviú' \\
\hline 90 & 130,42 bА & 165,34 bA & 55,15 ьв \\
\hline 100 & 271,60 aA & 275,59 aА & 67,73 abB \\
\hline 110 & $307,35^{\mathrm{aA}}$ & $270,76^{\text {aA }}$ & $102,48 \mathrm{aB}$ \\
\hline \multirow[t]{2}{*}{$\mathrm{CV} \%$} & & 25,75 & \\
\hline & \multicolumn{3}{|c|}{ Ácido ascórbico (mg $\left.100 \mathrm{~g}^{-1}\right)$} \\
\hline 90 & 3,33 aв & $8,23^{\text {aA }}$ & $8,04^{\mathrm{aA}}$ \\
\hline 100 & 4,94 ав & 9,57 aA & 6,79 abв \\
\hline 110 & 5,00 ав & 7,89 aA & 4,90 ьв \\
\hline$\overline{\mathrm{CV} \%}$ & & 26,06 & \\
\hline
\end{tabular}

Médias seguidas da mesma letra minúscula, na coluna, e da mesma letra maiúscula, na linha, não diferem a p $<0,05$, pelo teste Tukey.
Os resultados do teor de ácido ascórbico encontrados neste trabalho (Tabela 2) são inferiores aos relatados por Santana et al. (2008), que verificaram teores médios de ácido ascórbico de 17,54 mg $100 \mathrm{~mL}^{-1}$ para o cultivar Patrícia, mas foram superiores aos relatados por Detoni et al. (2005), que verificou teores ao redor de $1,0 \mathrm{mg} 100 \mathrm{~mL}^{-1}$ para o cultivar Niágara Rosada. Sob o aspecto nutricional, a uva 'Bordô' para o consumo in natura é uma fonte relativamente baixa de ácido ascórbico (Vitamina C), quando comparada com outras frutas comercializadas, como manga 'Ubá', abacaxi 'Pérola' e laranja 'Pêra', cujos teores de ácido ascórbico são em média 53,70 (Silva et al., 2009), 17,65 (Reinhardt et al., 2004) e 62,50 mg $100 \mathrm{~mL}^{-1}$ (Couto \& Canniatti-Brazaca, 2010), respectivamente. O índice de fenóis totais, denominado I280, baseia-se na absorbância da amostra no comprimento de onda de 280 ๆm, cujo máximo de absorbância ocorre para substâncias características de ciclo benzênico, que representam a maioria dos compostos fenólicos da uva, sendo uma variável de referência utilizada, por diversos autores, para quantificação do aporte fenólico de uvas (Bevilaqua, 1995; Rizzon \& Miele, 2004; Silva et al., 2008; Mota et al., 2009).

Com relação ao índice de fenóis totais da polpa, verificou-se efeito significativo ( $\mathrm{p}<0,01)$ do porta-enxerto, com destaque para o '420A', que, para as uvas cultivadas sobre ele, propiciou índices de fenóis totais da polpa superiores aos das uvas cultivadas sobre os demais porta-enxertos nos dois últimos períodos de colheita (Tabela 3).

A relevância do efeito significativo $(p<0,01)$ da interação entre os fatores avaliados, conforme a Análise de Variância, pode ser verificada nos resultados para as uvas avaliadas sobre os porta-enxertos '420A' e 'IAC766’ (Tabela 3), que influenciaram em acréscimos nos índices fenólicos da polpa em decorrência do avanço do período de colheita, quando se comparam com os das uvas avaliadas sobre 'Ripária-do-Traviú’, que mostram diminuição significativa no índice fenólico, no último período de colheita. Esses resultados sugerem que, dependendo do porta-enxerto, diferentes respostas no teor de fenóis totais podem ocorrer com a maturação fisiológica, pois conforme relatado por Beer et al. (2002) e Abe et al. (2007), o teor de compostos fenólicos totais nas bagas pode variar conforme uma série de fatores, mas que a adaptabilidade ao clima e ao solo e a influência no vigor da planta, associados ao sombreamento das bagas, são características importantes do porta-enxerto que devem ser consideradas.

Há de se considerar também que os compostos fenólicos possuem funções determinantes para a planta e que seu acúmulo na baga está relacionado, entre outros fatores, com o estresse gerado pelo clima ou por patógenos. Neste caso, a incidência elevada de luz ultravioleta sobre os tecidos de frutos pode promover 
maior acúmulo destes metabólitos, graças à ativação de genes responsáveis pela sua rota de síntese no metabolismo secundário (Chitarra \& Chitarra, 2005).

Com relação à influência sobre o índice de fenóis totais da epiderme (Tabela 3), o porta-enxerto ‘420A' foi significativamente superior aos demais em estudo, sugerindo seu maior acúmulo de fenóis totais. Por outro lado, a tendência de menor acúmulo de compostos fenólicos das uvas cultivadas sobre 'Ripária-do-Traviú' reforça a tese de sua menor adaptação às condições edafoclimáticas impostas e, consequentemente, suas qualidades enológica e nutricional inferiores.

Os efeitos significativos do período de colheita sobre os fenóis totais da epiderme (Tabela 3) revelam que, com exceção das uvas cultivadas sobre 'Ripária-do-traviú', houve acréscimos no índice I280 apenas do primeiro para o segundo período, não havendo acúmulos significativos do segundo para o terceiro período de colheita, considerado como sobrematuração da baga, o que discorda dos resultados de Pommer (2003), que relatou que a sobrematuração ocorre quando não há mais acúmulo significativo de açúcares na baga, nem expressiva queda de acidez, mas com os teores de compostos fenólicos tendendo a aumentar nesta fase.

Em outra análise, o índice de fenóis totais (I280) também pode ser utilizado como referência para a elaboração de vinhos. Conforme relatado no trabalho de Silva et al. (2008), uvas com I280 acima de 60 devem ser destinadas à elaboração de vinhos de melhor qualidade; as com índices entre 55 e 45, para vinhos jovens, e aquelas com índices abaixo de 40 para vinhos considerados de baixa qualidade. Com base nessas afirmações e considerando-se os resultados da Tabela 3, a uva 'Bordô' avaliada sobre o porta-enxerto '420A' apresentou índices satisfatórios na polpa (40,50 e 44,60, aos 100 e 110 dias da floração, respectivamente), para produzir vinho acima do que é considerado de baixa qualidade, sugerindo sua melhor adapta- bilidade, quando se compara com a mesma uva avaliada sobre outros porta-enxertos testados. O índice I280 é um indicador que pode ser utilizado para qualificar vinhos, mas não deve ser utilizado como único fator de avaliação, pois a qualidade de vinhos é definida por diversos fatores, como já reportado.

De acordo com a Análise de Variância, constatou-se que os porta-enxertos testados não influenciaram significativamente no acúmulo de taninos da polpa da uva 'Bordô'. Porém, em relação ao fator período de colheita, a ocorrência de efeito significativo $(p<0,05)$ refletiu-se, conforme apresentado na Tabela 3 , em aumentos seguidos de diminuições significativas de taninos da polpa, com o avanço do período de colheita, para os três portaenxertos.

A ocorrência de variações hormonais na videira é responsável por fenômenos metabólicos que marcam o fim da etapa vegetativa e o início da maturação das bagas (Pommer, 2003). Nesta transição, o metabolismo secundário das pentoses passa a ser mais utilizado para a síntese fenólica, via fenilalanina, para a formação de compostos fenólicos, como taninos, antocianinas e outros flavonoides (Castro et al., 2005), até o amadurecimento total das bagas. Isso deve ter ocorrido até o período de 100 dias da floração (Tabela 3), explicando os aumentos significativos nos teores de taninos da polpa e da epiderme, a partir do qual reações de degradação prevaleceram apenas na polpa das bagas.

Foi relatado que o acréscimo no teor de taninos nas bagas ocorre até a fase de "véraison”, caracterizada pela mudança de coloração das bagas nas uvas tintas, decrescendo logo nas primeiras fases da maturação (Ide et al., 1993; Jordão et al., 2001; Mateus et al., 2001; Ó-Marques et al., 2005), contrastando com os resultados verificados na Tabela 3.

Em relação à concentração de tanino na epiderme, constatou-se que as uvas avaliadas sobre os porta-enxertos

Tabela 3. Índices de fenóis totais (I280) e taninos da polpa e da epiderme da uva ‘Bordô' em diferentes porta-enxertos e períodos de colheita

\begin{tabular}{|c|c|c|c|c|c|c|}
\hline \multirow{2}{*}{$\begin{array}{l}\text { Períodos de } \\
\text { colheita (dias) }\end{array}$} & \multicolumn{3}{|c|}{ Índice de fenóis totais da polpa } & \multicolumn{3}{|c|}{ Índice de fenóis totais da epiderme } \\
\hline & '420A' & 'IAC-766' & 'Ripária-do-Traviú' & '420A' & 'IAC-766' & 'Ripária-do-Traviú' \\
\hline 90 & $32,00 \mathrm{bA}$ & 16,30 ьв & 32,70 aA & 26,93 bA & 14,81 ьв & 14,03 aв \\
\hline 100 & $40,50^{\mathrm{aA}}$ & 20,50 ьв & 25,40 ав & $38,66^{\text {aA }}$ & 26,31 ав & $13,43 \mathrm{ac}$ \\
\hline 110 & 44,60 aA & 28,60 ав & 14,30 bc & $37,41^{\mathrm{aA}}$ & 26,40 ав & $16,66^{\mathrm{aC}}$ \\
\hline \multirow[t]{2}{*}{$\overline{\mathrm{CV} \%}$} & \multicolumn{3}{|c|}{21,57} & \multicolumn{3}{|c|}{25,22} \\
\hline & \multicolumn{3}{|c|}{ Taninos da polpa $\left(\mathrm{mg} \mathrm{g}^{-1}\right)$} & \multicolumn{3}{|c|}{ Taninos da epiderme $\left(\mathrm{mg} \mathrm{g}^{-1}\right)$} \\
\hline 90 & $1,89 \mathrm{bA}$ & $2,06^{\mathrm{abA}}$ & $1,76^{\mathrm{bA}}$ & $3,03 \mathrm{bA}$ & $3,84^{\mathrm{bA}}$ & $0,87^{\mathrm{bB}}$ \\
\hline 100 & 2,19 aA & 2,28 aA & $2,16^{\mathrm{aA}}$ & $4,90^{\mathrm{aA}}$ & $6,55^{\text {aA }}$ & 2,73 ав \\
\hline 110 & $1,78 \mathrm{bA}$ & 1,87 bA & $1,70 \mathrm{bA}$ & 5,29 aA & $5,84^{\mathrm{aA}}$ & $3,68{ }^{\mathrm{aB}}$ \\
\hline$\overline{\mathrm{CV} \%}$ & & 15,73 & & & 25,34 & \\
\hline
\end{tabular}

Médias seguidas da mesma letra minúscula, na coluna, e da mesma letra maiúscula, na linha, não diferem a p < 0,05, pelo teste Tukey.

Rev. Ceres, Viçosa, v. 59, n.5, p. 701-708, set/out, 2012 
'420A' e ‘IAC-766’ apresentaram concentrações superiores àquela encontrada nas avaliadas sobre o porta-enxerto 'Ripária-do-Traviú' (Tabela 3), revelando características viníferas superiores destes dois porta-enxertos.

Independentemente dos fatores de variação estudados, verificou-se que o acúmulo de taninos foi maior na casca (Tabela 3), concordando com Kennedy et al. (2001), que relataram que as maiores concentrações de taninos ocorrem na casca e nas sementes de uvas e são quase ausentes na polpa. Porém, conforme afirmações de Tecchio et al. (2007), as uvas de variedades americanas, como é o caso da 'Bordô', em geral possuem baixos teores de taninos, quando comparadas com as variedades viníferas, evidenciando a baixa aptidão para o amadurecimento e, ou, envelhecimento de seu vinho.

É relevante salientar que o aumento da concentração de taninos em uvas, conforme relatado por Silva et al. (2009), pode ser explicado pelo estresse oxidativo proporcionado por fatores ambientais, como as doenças fúngicas como o mofo-cinzento, e a podridão da uva madura, proximamente à colheita, pois um dos sistemas de defesa da planta contra o desenvolvimento de agentes fitopatogênicos está na síntese de substâncias fungistáticas, inclusive polifenóis, como taninos, que possuem atividade antimicrobiana.

\section{CONCLUSÕES}

A uva 'Bordô' apresentou respostas similares em acúmulos de antocianinas, taninos, acidez titulável e sólidos solúveis, quando enxertada nos porta-enxertos ' $420 \mathrm{~A}$ ' e 'IAC-766', mas os acúmulos de fenóis totais, tanto na polpa quanto na epiderme das bagas, foram maiores quando sobre o '420A'.

O teor de ácido ascórbico foi mais elevado na uva 'Bordô' quando enxertada em 'IAC-766'.

Menores acúmulos de antocianinas, fenóis totais e taninos da epiderme da uva 'Bordô', quando enxertada em 'Ripária-do-Traviú', evidenciam inferioridade deste porta-enxerto para os aspectos nutricionais e enológicos.

\section{REFERÊNCIAS}

Abe LT, Mota RV, Lajolo FM \& Genovese MI (2007) Compostos fenólicos e capacidade antioxidante de cultivares de uvas Vitis labrusca L. e Vitis vinifera L. Ciência e Tecnologia de Alimentos, 27:394-400.

Alvarenga AA, Regina MA, Fráguas JC, Chalfun NNJ \& Silva AL (2002) Influência do porta-enxerto sobre o crescimento e produção da cultivar de videira niágara rosada (Vitis labrusca L. $\mathrm{x}$ Vitis viniferea L.), em condições de solo ácido. Ciência e Agrotecnologia, 26:1459-1464.

Beer D, Joubert E, Gelderblom WCA \& Manley M (2002) Phenolic compounds: a review of their possible role as in vivo antioxidants of wine. South African Journal of Enology and Viticulture, 23:48-61.
Benassi MT \& Antunes AJA (1988) Comparison of metaphosphoric and oxalic acids as extractant solutions for the determination of vitamin $C$ in selected vegetables. Arquivos de Biologia e Tecnologia, 31:507-513.

Bevilaqua GAP (1995) Avaliações físico-químicas durante a maturação de videiras cultivadas no Rio Grande do Sul. Revista Brasileira de Agrociência, 1:151-156.

Carvalho CRL, Mantovani DMB, Carvalho PRN \& Moraes RMM (1990) Análises químicas de alimentos. Campinas, Instituto de Tecnologia de Alimentos. 85p.

Castro PRC, Kluge RA \& Peres LEP (2005) Manual de fisiologia vegetal: Teoria e prática. São Paulo, Editora Agronômica Ceres. 650 p.

Cheftel J \& Cheftel H (1992) Introducion a la bioquímica y tecnología de los alimentos. v 1. Zaragoza, Acribia. 333p.

Chitarra MIF \& Chitarra AB (2005) Pós-colheita de frutos e hortaliças: Fisiologia e manuseio. 2 ed. Lavras, UFLA. 785p.

Couto MAL \& Canniatti-Brazaca SG (2010) Quantificação de vitamina $\mathrm{C}$ e capacidade antioxidante de variedades cítricas. Ciência e Tecnologia de Alimentos, 30:15-19.

Detoni AM, Clemente E, Braga GC \& Herzog NFM (2005) Uva 'niágara rosada' cultivada no sistema orgânico e armazenada em diferentes temperaturas. Ciência e Tecnologia de Alimentos, 25:546-552.

Gonçalves CAA, Regina MA, Chalfun NNJ, Alvarenga AA, Abrahão E \& Berzoti E (1999) Comportamento da cultivar folha de figo (Vitis labrusca L.) sobre diferentes porta-enxertos de videira. Revista Brasileira de Fruticultura, 21:7-11.

Haslam E \& Lilley T (1988) Natural astringency in foodstuffs: a molecular interpretation. Critical Reviews in Food Science and Nutrition, 27:1-40.

Ide GM, Rizzon LA \& Daudt CE (1993) Influência do tempo de maceração do vinho 'isabel' e 'merlot'. Boletim da Sociedade Brasileira de Ciência e Tecnologia de Alimentos, 27:88-95.

Jordão A, Ricardo-da-Silva JM \& Laureano O (2001) Evolution of cathechins na oligomeric procyanidins during grape maturation of Castelão Francês and Touriga Francesa. American Journal of Enology and Viticulture, 52:230-234.

Kennedy JA, Hayasaka Y, Vidal S, Water EJ \& Jones GP (2001) Composition of grape skin proanthocyanidins at different stages of berry development. Journal of Agricultural and Food Chemistry, 49:5348-5355.

Lee J, Rennaker C \& Wrolstad RE (2008) Correlation of two anthocyanin quantification methods: HPLC and spectrophotometric methods. Food Chemistry, 110:782-786.

Mandelli F, Miele A, Rizzon LA \& Zanus MC (2008) Efeito da poda verde na composição físico-química do mosto da uva Merlot. Revista Brasileira de Fruticultura, 30:667-674.

Mateus N, Marques S, Gonçalves A, Machado J \& Freitas V (2001) Proanthocyanidin composition of red Vitis vinífera varieties from Douro valley during repening: influence of cultivation altitude. American Journal of Enology and Viticulture, 52:11512 .

Mota RV, Souza CR, Favero AC, Silva CPC, Carmo EL, Fonseca AR \& Regina MA (2009) Produtividade e composição físicoquímica de bagas de cultivares de uva em distintos porta-enxertos. Pesquisa Agropecuária Brasileira, 44:576-582.

Muñoz-Espada AC, Wood KV, Bordelon B \& Watkins BA (2004) Anthocyanin quantification and radical scavening capacity of concord, norton, and marechal foch grapes and wines. Journal of Agricultural and Food Chemistry, 52:6779-6786.

Rev. Ceres, Viçosa, v. 59, n.5, p. 701-708, set/out, 2012 
Ó-Marques J, Reguinga R, Laureano O \& Ricardo-da-Silva JM (2005) Changes in grape seed, skin and pulp condensed tannins during berry ripening: effect of fruit pruning. Ciência e Técnica Vitivinícola, 20:35-52.

Orak HH (2007) Total antioxidant activities, phenolics, anthocyanins, polyphenoloxidase activities of selected red grape cultivars and their correlations. Scientia Horticulturae, 111:235241.

Orlando TGS, Pedro Junior MJ, Santos AO \& Hernades JL (2008) Yield-related performance of cv. Cabernet sauvingnon and petite syrah on different rootstocks. Ciência e Agrotecnologia, 32:749755.

Pommer CV (2003) Uva: Tecnologia de produção, pós-colheita, mercado. Porto Alegre, Cinco Continentes. 778p.

Reinhardt DH, Medina VM, Caldas RC, Cunha GAP \& Estevam RFH (2004) Gradientes de qualidade em abacaxi 'Pérola' em função do tamanho e do estádio de maturação do fruto. Revista Brasileira de Fruticultura, 26:544-546.

Rice-Evans CA, Miller NJ \& Paganga G (1996) Structure antioxidant activity relationship of flavonoids and phenolic acid. Free Radical in Biology and Medicine, 20:933-956.

Rizzon LA \& Miele A (2004) Avaliação da cv. Tannat para elaboração de vinho tinto. Ciência e Tecnologia de Alimentos, 24:223-229.

Rizzon LA, Miele A \& Meneguzzo J (2000) Avaliação da uva cv. Isabel para a elaboração de vinho tinto. Ciência e Tecnologia de Alimentos, 20:115-121.

SAEG (2007) Sistema para análises estatísticas. Versão 9.1, Viçosa, Fundação Arthur Bernardes, UFV.
Santana MTA, Siqueira HH, Lacerda RJ \& Lima LCO (2008) Caracterização físico-química e enzimática de uva 'patrícia' cultivada na região de Primavera do Leste - MT. Ciência e Agrotecnologia, 32:186-190.

Sato AJ, Silva BJ, Santos CE, Bertolucci R, Santos R, Carielo M, Guiraud MC, Fonseca ICB \& Roberto SR (2008) Características físico-químicas e produtivas das uvas 'Isabel' e 'BRS-rúbea' sobre diferentes porta-enxertos na região norte do Paraná. Revista Brasileira de Fruticultura, 30:553-556.

Silva DFP, Siqueira DL, Pereira CS, Salomão LCC \& Struiving TB (2009) Caracterização de frutos de 15 cultivares de mangueira na Zona da Mata mineira. Revista Ceres, 56:783-789.

Silva LC, Rufato L, Kretzschmar AA \& Marcon Filho JL (2009) Raleio de cachos em vinhedos de altitude e qualidade do vinho da cultivar syrah. Pesquisa Agropecuária Brasileira, 44:148-154.

Silva LC, Kretzschmar AA, Rufato L, Brighenti AF \& Schlemper C (2008) Níveis de produção em vinhedos de altitude do cv. Malbec e seus efeitos sobre os compostos fenólicos. Revista Brasileira de Fruticultura, 30:675-680.

Silva M \& Silva MAAP (1999) Aspectos nutricionais de fitatos e taninos. Revista de Nutrição, 12:5-19.

Tecchio FM, Miele A \& Rizzon LA (2007) Características sensoriais do vinho 'bordô'. Pesquisa Agropecuária Brasileira, 42:897899.

Teissedre PL \& Landrault N (2000) Wine phenolics: contribution to dietary intake and bioavailability. Food Research International, 33:461-467.

Wang H, Cao G \& Prior R (1997) Oxygen radical absorbing capacity of anthocyanins. Journal of Agricultural and Food Chemistry, 45:304-309. 